\title{
Increasing Proliferation of Intrinsic Tubular Cells after Renal Ischemia-reperfusion Injury in Adult Rat
}

\author{
Jian Feng ${ }^{1}$, Weiming Hu${ }^{1}$, Chunyue Feng ${ }^{1}$, XiaoOu Mao ${ }^{2}$, Kunlin $\operatorname{Jin}^{3}$ and Youxin $\mathrm{Ye}^{1}$ \\ ${ }^{1}$ Department of Nephrology, Sir Run Run Shaw Hospital, Zhejiang University School of Medicine, Zhejiang \\ 310016, China \\ ${ }^{2}$ Buck Institute for Research on Aging, Novato, CA94945, USA \\ ${ }^{3}$ Department of Pharmacology and Neuroscience, University of North Texas Health Science Center, Fort Worth, \\ TX76107, USA
}

[Received August 14, 2013; Revised September 11, 2014; Accepted September 17, 2014]

\begin{abstract}
The kidney is capable of regeneration following injury. However, whether renal stem/progenitor cells contribute to the repair process after injury, as well as the origin of the cells that repair and replace damaged renal tubule cells remains debated. Therefore, better understanding of the repair process will be critical to developing new strategies for the treatment of acute renal failure. Using an ischemia-reperfusion injury mode and an immunocytochemistry method, we counted the number of BrdU-positive cells in damged regions at different durations of reperfusion. We found that BrdU, a cell proliferative marker, was mainly incorporated in the tubular cells of both medulla and cortex 1 day after reperfusion. The number of BrdU-positive cells reached a peak at 3 days and lasted for two months after injury. BrdU-positive cells were barely found in the renal glomerulus and the parietal layer of Bowman's capsule after injury, and only a few were found in the intersititium. PAX2, an embryonic renal marker, was also increased in renal tubule cells. Confocal images show that BrdU-positive cells co-expressed PAX2, but not the activated form of caspase-3, a cell death marker. Our data suggest that renal stem-like cells or dedifferentiation of surviving renal tubular cells in both the medulla and cortex may predominantly contribute to the repair process after renal ischemia-reperfusion injury in rat.
\end{abstract}

Key words: kidney, ischemia-reperfusion injury, renal stem cells, proliferative cells, Pax-2, Adult

Acute renal failure (ARF), also known as acute kidney injury, is a rapid loss of renal function due to kidney damage, resulting in the retention of nitrogenous and nonnitrogenous waste products normally excreted by the kidney. Depending on the degree of injury, kidneys are generally capable of regeneration in response to the injury. When the injury is less severe, renal tubules can regenerate and restore normal or near normal renal function; however, in cases of more severe injury, regenerative capacity can be significantly reduced or even fail completely. Therefore, better understanding of the repair process will be critical to developing new strategies for improving the rate and degree of recovery after ARF.
The repair process of damaged tubules is achieved by the replacement of dead cells with newborn epithelial cells. The origin of these newly generated cells remains controversial [1]. Several lines of evidence suggest that surviving tubular epithelial cells de-differentiate and proliferate, eventually replacing the irreversibly injured tubular epithelial cells and restoring tubular integrity [2]. Recent studies show that putative native stem cells may be present in the adult kidney, which are located amongst the tubular cell population [3-6], in the Bowman's capsule [7], the papillary region $[8,9]$ or the cortical interstitium [10]. These native stem cells have been indicated to play an important role in epithelial repair after injury. A more

*Correspondence should be addressed to: Youxin Ye, M.D., Department of Nephrology, Sir Run Run Shaw Hospital Zhejiang University School of Medicine, Hangzhou, Zhejiang 310016, China. Email: yeyouxin333@163.com 
recent study suggests that regeneration by surviving tubular epithelial cells is the predominant mechanism of repair after ischemic tubular injury in mouse kidney [11]. Although previous studies show that bone marrowderived stem cells are able to migrate into the kidney and repopulate the renal tubular system after injury [12-14], these cells constitute only a small population and may not significantly contribute to the restoration of epithelial integrity after an ischemic insult $[15,16]$.

In the present study, we examined the profile of dividing cells in response to ischemic injury of adult kidney at different durations of reperfusion. We found that tubular cells were proliferative after ischemiareperfusion injury, which were found at 1 day, peaked at 3 days, and lasted for 56 days after renal ischemia. The majority of dividing cells were predominantly present in the tubule, and only a few of proliferative cells were observed in the intersititium and barely in the renal glomerulus and the parietal layer of Bowman's capsule after injury. Double immunostaining indicated that the dividing cells expressed stem/progenitor cell markers, but not cell death markers, suggesting the involvement of intrinsic stem-like epithelial cells or dedifferentiation of renal epithelial cells may mainly contribute to the renal functional recovery after ischemia-reperfusion injury in rat.

\section{MATERIALS AND METHODS}

\section{Transient renal ischemia}

Sprague-Dawley rats weighing about $220 \mathrm{~g}$ were anaesthetized with Chloral Hydrate. The abdomen was opened, and the left renal artery was carefully isolated and occluded for 60 min with microaneurysm clamps. During the period of ischemia, body temperature was maintained by placing the rats on a $37^{\circ} \mathrm{C}$ heating pad. After removal of the clamps, the kidneys were inspected for $1 \mathrm{~min}$ for restoration of blood flow, returning to their original color. The abdomen was then closed. Sham-operated rats $(n=6$ per group) received identical surgical procedures except that microaneurysm clamps were not applied. Rats were sacrificed at different durations after ischemic injury. All animal studies have been approved by the Institutional Review Board at Sir Run Run Shaw Hospital of Zhejiang University School of Medicine, China.

\section{Administration of Bromodeoxyuridine (BrdU)}

BrdU (100 mg/kg in saline, Sigma) was intraperitoneally given once after induction of ischemia-reperfusion injury. Rats were killed at 1, 3, 5, 7, 14, 21, 28, 56 days after injury. Kidney tissues were divided up to be either embedded in OCT compound and frozen or fixed in $4 \%$ paraformaldehyde for paraffin embedding.

\section{Histological examination}

Kidneys embedded in paraffin were sectioned at $5 \mu \mathrm{m}$ and stained with hematoxylin and eosin (H\&E, Vector Laboratories) by standard methods.

\section{Immunohistochemistry}

To detect BrdU-labeled cells in tissue sections, paraffin sections were treated with $50 \%$ formamide, $280 \mathrm{mM} \mathrm{NaCl}$, and $30 \mathrm{mM}$ sodium citrate at $65^{\circ} \mathrm{C}$ for $2 \mathrm{hr}$, incubated in 2 $\mathrm{M} \mathrm{HCl}$ at $37^{\circ} \mathrm{C}$ for $30 \mathrm{~min}$, and rinsed in $0.1 \mathrm{M}$ boric acid $(\mathrm{pH} 8.5)$ at room temperature for $10 \mathrm{~min}$. Sections were then incubated in $1 \% \mathrm{H}_{2} \mathrm{O}_{2}$ for $30 \mathrm{~min}$, and in blocking solution ( $2 \%$ goat serum, $0.1 \%$ Triton $\mathrm{X}-100$, and $1 \%$ bovine serum albumin in PBS) for $2 \mathrm{hr}$ at room temperature, before being treated with mouse monoclonal anti-BrdU (1:100; Santa Cruz Biotechnology, Santa Cruz, CA) overnight at $4^{\circ} \mathrm{C}$. To detect the expression of PAX2 (1:500; Zymed), immunohistochemistry was conducted on paraffin sections using a standard protocol with antigen retrieval, according to the manufacturer's instructions (Vector Laboratories). Sections were washed with PBS, incubated with biotinylated goat anti-mouse or anti-rabbit IgG secondary antibody (Vector Laboratories; 1:200) for $2 \mathrm{hr}$ at $25^{\circ} \mathrm{C}$, washed, and placed in avidin-peroxidase conjugate solution (Vector Laboratories) for $1 \mathrm{hr}$. The horseradish peroxidase reaction was detected with $0.05 \%$ diaminobenzidine (DAB) and $0.03 \% \mathrm{H}_{2} \mathrm{O}_{2}$. Processing was stopped with $\mathrm{H}_{2} \mathrm{O}$ and sections were dehydrated through graded alcohols, cleared in xylene, and coverslipped in permanent mounting medium (Vector Laboratories). Sections were examined with a Nikon E800 microscope. Controls included omitting the primary and secondary antibodies.

\section{Double label Immunostaining}

Double label immunostaining was performed on renal sections as previously described [17]. The primary antibodies used, in addition to BrdU and PAX2, were 1) mouse monoclonal nestin (1:200; BD Pharmingen); 2) goat polyclonal anti-human-specific Vimentin (1:200; Chemicon); 3) rabbit anti-cleaved caspase 3 (1:200; BD PharMingen, San Diego, CA). The secondary antibodies were Alexa Fluor 488-, 594-, or 647-conjugated donkey anti-mouse, anti-goat, or anti-rabbit IgG (1:200-500; Molecular Probes, Carlsbad, CA). Fluorescence signals were detected using an LSM 510 NLO Confocal Scanning System mounted on an Axiovert 200 inverted microscope 
(Carl Zeiss Ltd) equipped with a two-photon Chameleon laser (Coherent Inc.). Images were acquired using LSM 510 Imaging Software (Carl Zeiss Ltd). Selected images were viewed at high magnification. Controls will include omitting either the primary or secondary antibody or preabsorbing primary antibody.

\section{Cell counting}

BrdU-positive cells in the renal tissues were blindly counted in 5-7 DAB-stained paraffin sections per animal. At least 20 consecutive high-power fields (magnification, $\times 400$ ) per section were scored by 2 blinded operators. Images of BrdU-positive cells in the cortex and medulla counting were acquired using a Nikon E800 microscope and a Nikon DXM 1200 digital camera. The number of BrdU-positive cells in each region was determined using Simple PCI software. At least five animals were used per condition.

\section{Statistical analysis}

Quantitative results were expressed as the mean \pm SEM. The statistical significance of differences between means was evaluated using one-way analysis of variance (ANOVA). $\quad P<0.05$ was regarded as statistically significant.

\section{RESULTS}

Kidney ischemia-reperfusion injury was conducted to study the renal cell response to injury in adult rats (Figure 1A). As expected, this model was characterized by acute tubular cell death, which resulted eventually in the destruction of renal tissue (Figure 1B). With increased duration of reperfusion, renal function was gradually recovered, along with an increasing amount of surviving tubular cells.

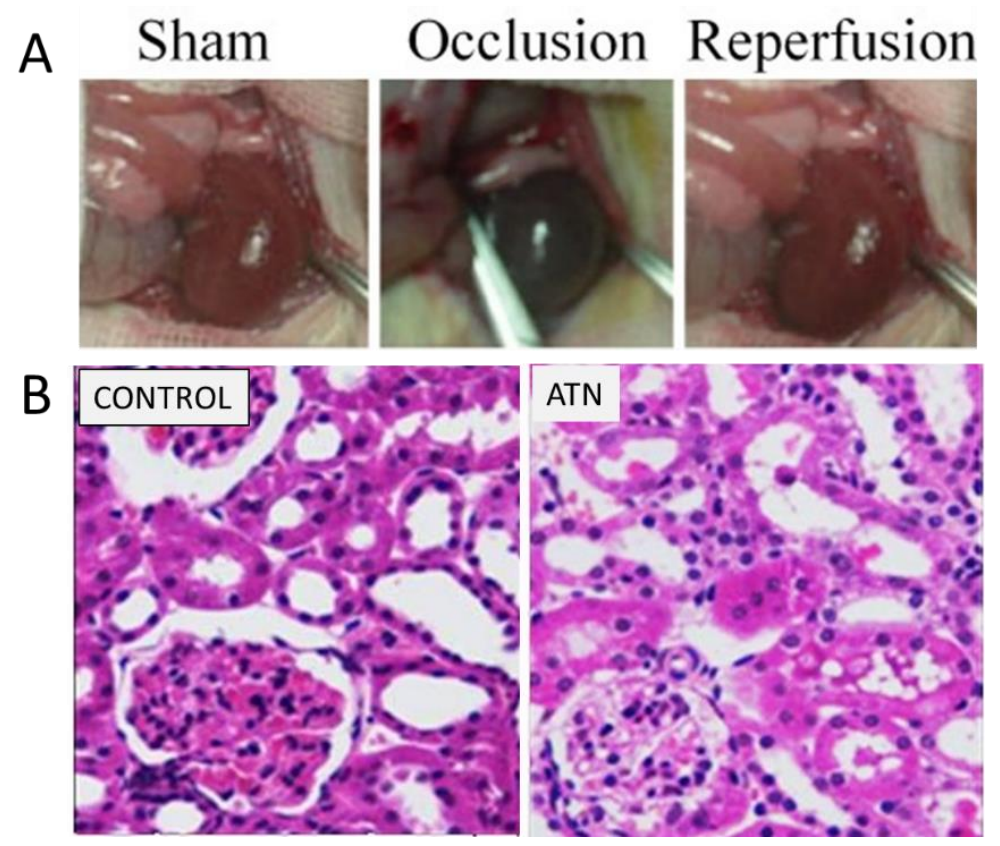

Figure 1. Induction of transient renal ischemia-reperfusion injury in rats. A. Representative pictures show induction of renal ischemia with reperfusion in rats. B. Left panel: representative microphotographs of a kidney section stained with H\&E from a sham-operated rat. Right panel: representative microphotographs of a kidney section stained with $\mathrm{H} \& \mathrm{E}$ from a renal ischemic rat. 

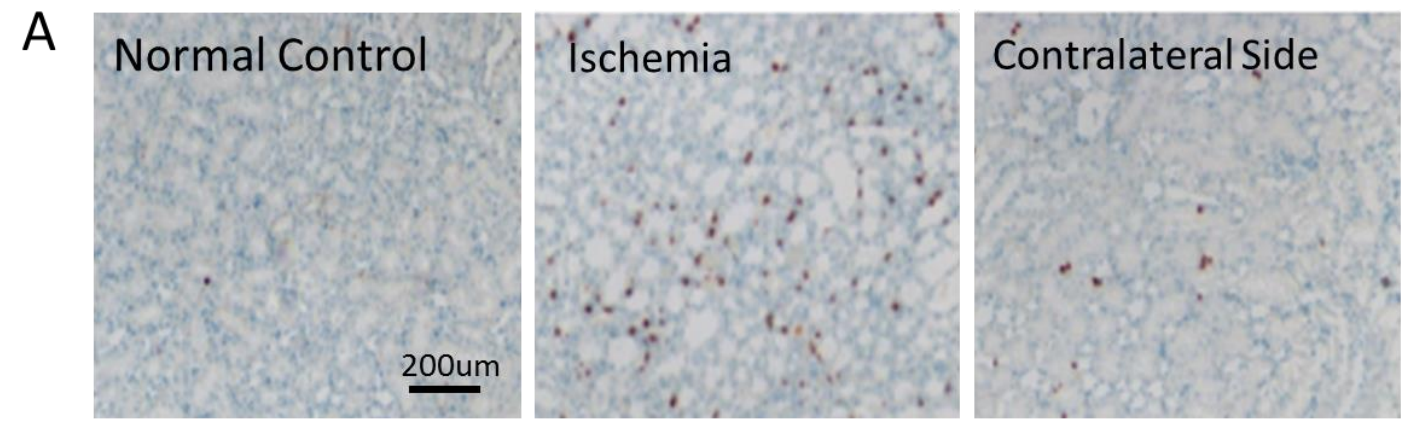

B

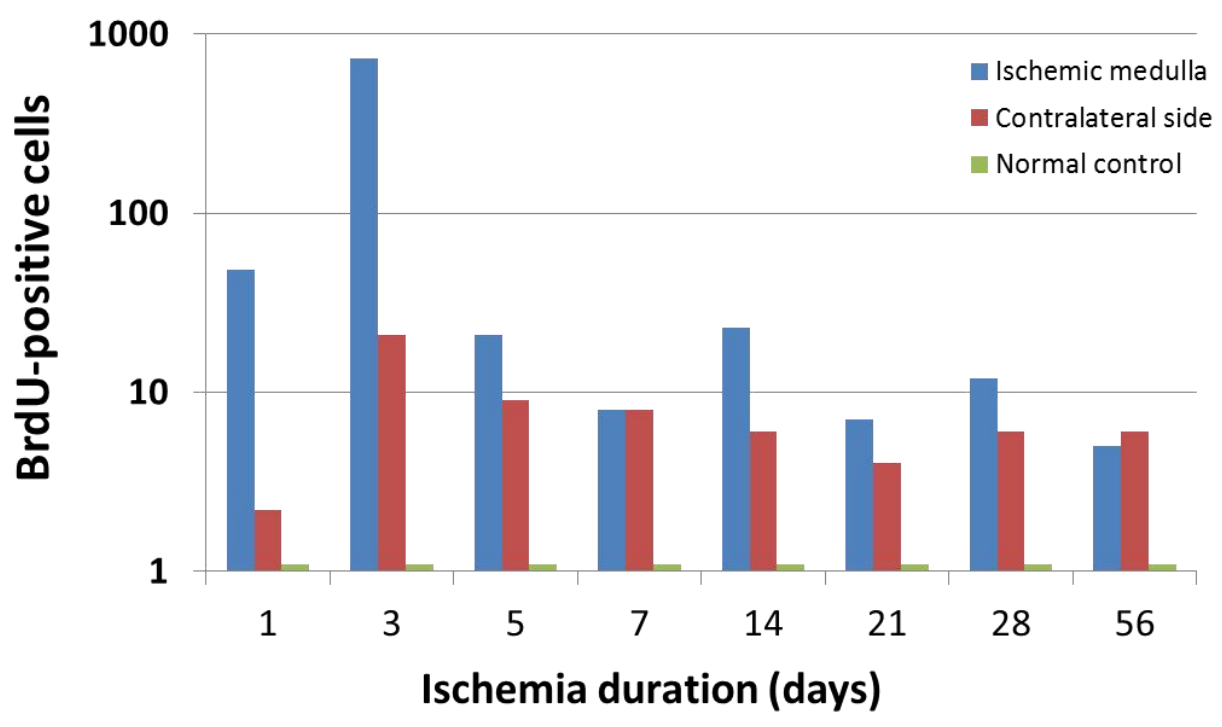

Figure 2: BrdU-positive cells were significantly increased in the adult kidney after renal ischemiareperfusion injury. A. BrdU-positive cells were barely detectable in the sham-operated rats (left panel: lowermagnification view). However, BrdU-positive cells (brown color) in the renal tubules were dramatically increased after transient renal ischemia (middle panel: low-magnification view). BrdU-positive cells in the contralateral side were also increased significantly to compare to that in the normal control, though it is lower than that in the transient renal ischemia. Representative microphotographs of a kidney section were obtained from 3 days after ischemia. Hematoxylin was used for nuclear staining. B. Quantitative analysis of BrdU-positive cells in the renal medulla with normal control, transient renal ischemia and contralateral side. Data shown are mean \pm SD. $n=6$ 8 per group.

To investigate whether renal ischemia-reperfusion injury could induce the dividing cells in the adult kidney, BrdU, a marker of proliferation, was administrated immediately after injury, and immunostaining was performed using anti-BrdU antibody. As shown in Figure 2, only a few of BrdU-positive cells were found in the sham-operated rats with a random distribution. BrdUpositive cells count were $0.25 \pm 0.25$ at 3 days. However, the number of BrdU-positive cells dramatically increased 1 day after injury with a peak at 3 days, and lasted for 56 days (Figure 2B). BrdU-positive cells count were 726.50 \pm 184.23 in injured regions at 3 days. In the contralateral side, BrdU-positive cells count were also increased, which was $7.25 \pm 1.38$. It was significantly higher than that in the normal control. Over 90\% BrdU-positive cells were found in the proximal and distal tubules of both the 
cortex and medulla of adult rat kidney at 3 and 56 days after ischemia injury. Only a few of BrdU-positive cells (2-10\%) were observed in the intersititium at 3 and 56 days after injury, while hardly any were seen in the renal glomerulus and in the parietal layer of Bowman's capsule.

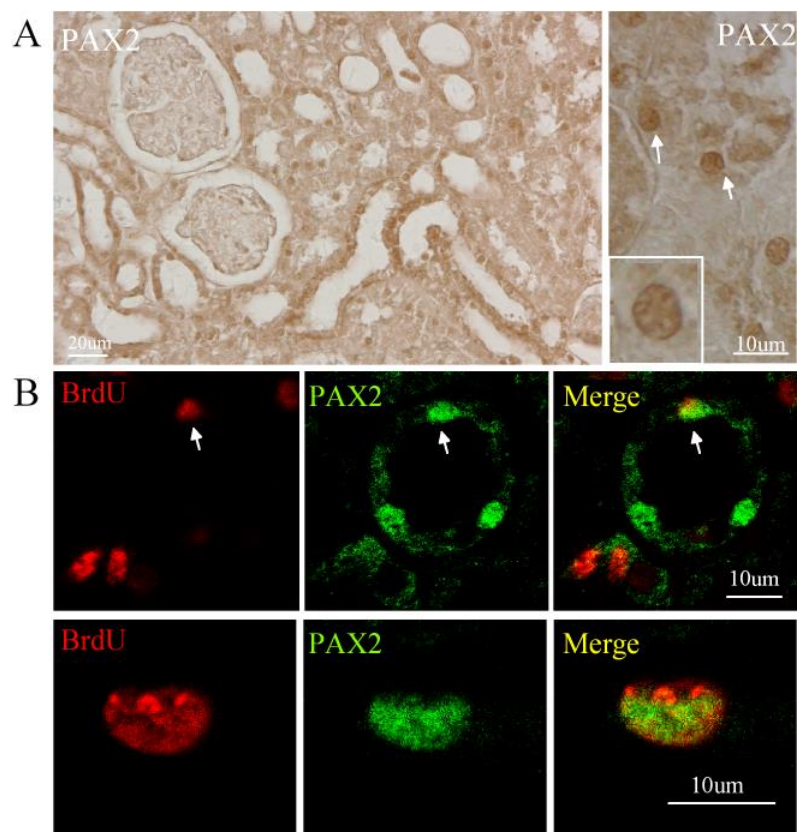

Figure 3. BrdU-positive cells expressed PAX2 in renal ischemia-reperfusion rat. A. PAX2 was expressed in the renal tissue 3 days after transient ischemia. Left panel: lowmagnification view; right panel: high-magnification view. B. BrdU-positive cells (red) expressed PAX2 (green) after injury. Top panel: low-magnification view; Bottom panel: highmagnification view. Representative microphotographs of a kidney section (middle right and right panel) were obtained from 3 days after ischemia.

To determine the phenotype of BrdU-positive cells in the kidney, we performed immunostaining using Pax2 antibody, since Pax 2 has been considered to be an embryonic renal marker. As shown in Figure 3A, we found that $\operatorname{Pax} 2$ was predominantly expressed in renal tubular cells in the ischemic kidney, but only slightly in sham-operated control group. Double immunocytochemistry shows that BrdU-positive cells in the renal tubule co-expressed $\mathrm{Pax}-2$ (Figure 3B), suggesting that these cells were likely dividing stem/progenitor cells or dedifferentiation cells. In addition, we also found that vimentin, immature cell markers, was expressed in the BrdU-positive cells (Figure 4B). Nestin, a marker of multi-lineage stem and progenitor cells was expressed located in the interstitial and glomerular regions, but barely in the tubule (Figure $4 \mathrm{~A})$.
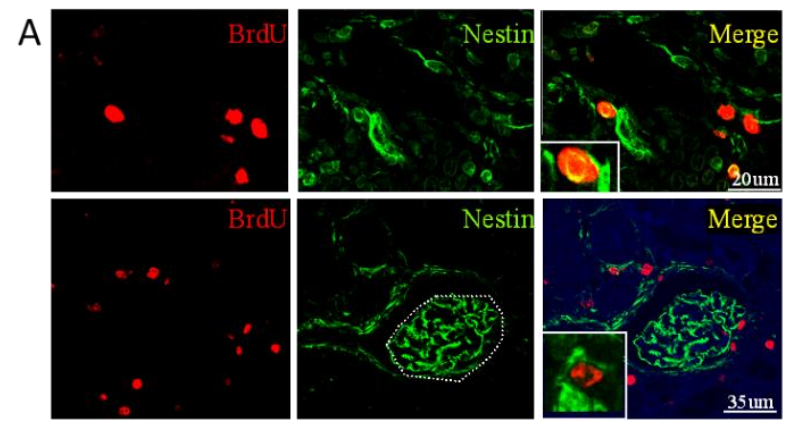

B
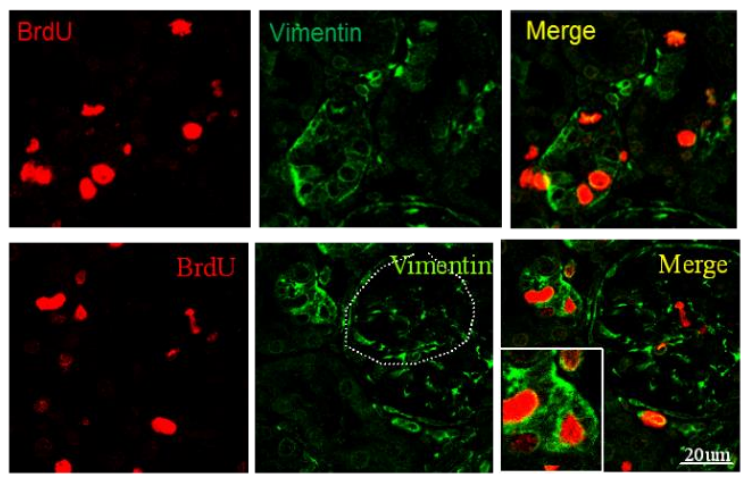

Figure 4. BrdU-positive cells expressed nestin and vimentin in adult kidney in rat. $\mathbf{A}$. BrdU-positive cells (red) in the tubule (top panel) and the glomerulus (bottom panel) expressed nestin (green). B. BrdU-positive cells (red) in the tubule (top panel) and the glomerulus (bottom panel) expressed vimentin (green). Representative microphotographs of a kidney section were from 3 days after ischemia.

Since BrdU may incorporate into the damaged DNA, we performed double immunostaining on the sections from 3, 15 and 56 days of reperfusion after injury using anti-BrdU and anti-activated form of caspase- 3 antibodies to exclude the possibility that BrdU-positive cells were dead cells. The images were recorded by two photon laser-scanning confocal microscopy. We found that BrdU-positive cells did not express caspase-3 (Figure 5), further indicating that these dividing cells might be renal stem/progenitor cells. 


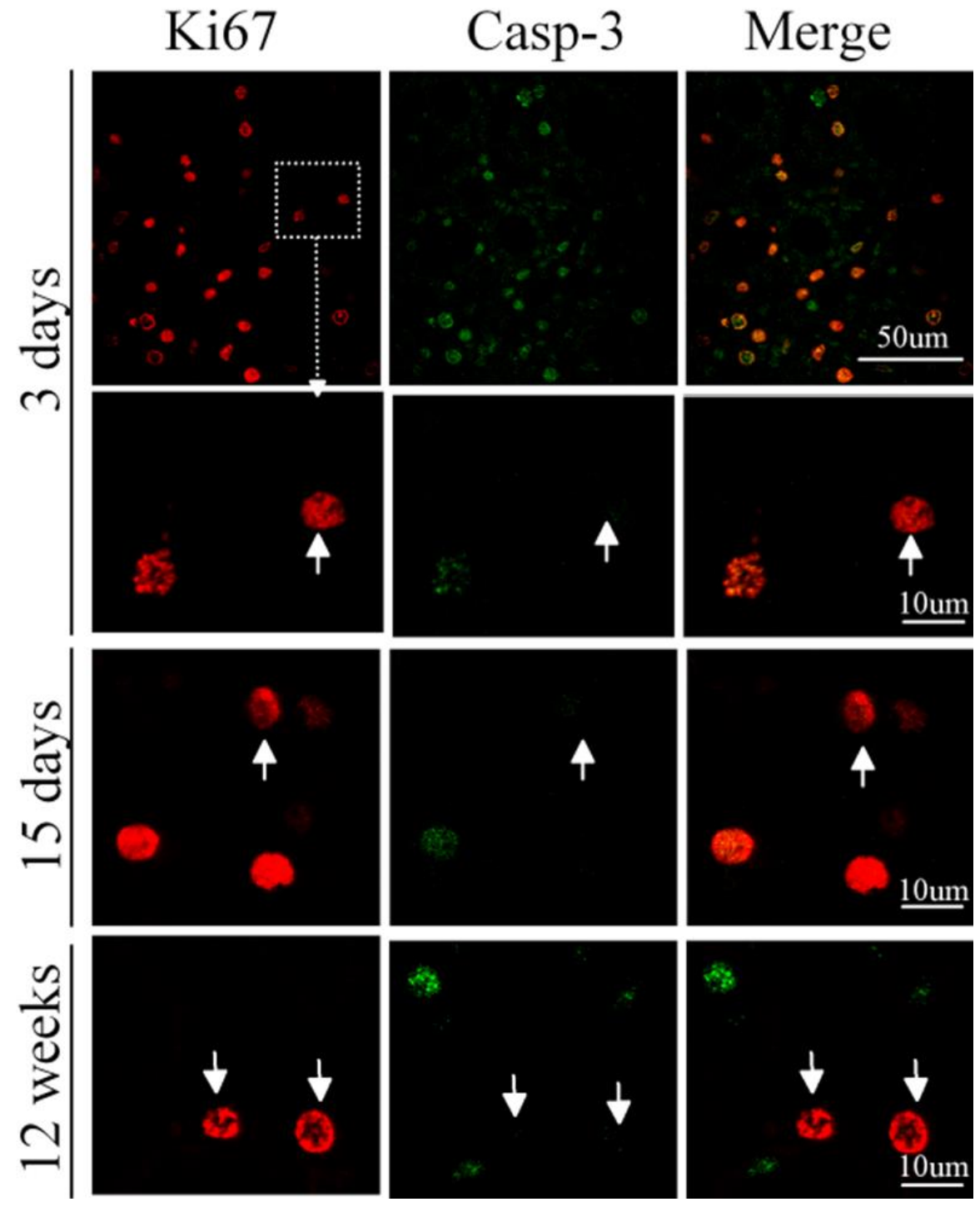

Figure 5. BrdU-positive cells in the renal tissue after ischemia did not express activated form of caspase-3. Double immunostaining was performed on the renal sections obtained from different durations of reperfusion as indicated. BrdU-positive cells did not expressed activated form of caspase-3, indicating that these cells were not apoptotic cells.

\section{DISCUSSION}

In this study, we found that dividing cells in the kidney were induced 1 day after ischemia-reperfusion injury, peaked at 3 days and lasted for two months. BrdU-positive cells were predominantly found in the proximal and distal tubules. However, only a few of BrdU-positive cells were observed in the intersititium and rarely in the glomeruli or parietal layer of Bowman's capsule. Immunostaining shows that an embryonic renal marker, PAX2, was induced and mainly expressed in the tubular epithelial cells after injury. Double immunostaining shows that BrdU-positive cells expressed PAX2, but not cell death marker cleaved caspase-3. Our data suggest that the repair of injured tubules may be mainly achieved by intrinsically stem-like or dedifferentiation of surviving epithelial cells.

Studies suggest that Pax2 is expressed in induced mesenchyme and early epithelial derivates during kidney development and that it is rapidly down-regulated in mature kidney [18]. In kidneys of normal adult Pax2 protein expression is limited to nuclei of collecting duct cells, with the highest expression in the renal papilla [19]. 
In this study, the reexpression of Pax2 in BrdU-positive cells in renal tubule after ischemia-reperfusion injury suggests a reversion to mesenchymal cell like phenotype. Consistent with this finding, immunocytochemischy also shows BrdU-positive cells coexpressed vimentin. Vimentin is the most ubiquitous intermediate filament protein. However, recent studies show that the renal tissue-derived CD133-positive cells express vimentin before they fully differentiate into epithelial cells [10], suggesting that vimentin is an immature marker of renal stem/progenitor cells [20]. The reexpression of Pax2 and vimentin in renal tubular BrdU-positive cells indicates these cells may be renal stem-like cells or these cells could be dedifferentiation of surviving tubular epithelial cells, which play a predominate role in tubular regeneration after renal ischemia-reperfusion injury.

Nestin is one of ubiquitous intermediate filament protein, which is originally identified in neuroepithelial stem cells. Therefore, this protein has been widely used as a predominant marker for neural stem/progenitor cells [21]. Recent studies show that nestin is induced in renal tubular and interstitial cells in the adult rat kidney following unilateral ureteral obstruction [22], and is also highly expressed in glomerular cells, interstitial cells and podocytes in normal adult human kidney [23]. We noted that although nestin is abundantly expressed in the glomeruli, only a few BrdU-positive cells are found in this region. Therefore, it is possible that cells in the regions may not be significantly affected by ischemia-reperfusion injury. In addition, we found that the profile of PAX2 expression is different from that of nestin; it is possible that they are expressed in the different subpopulation of cells.

BrdU is not only incorporated into dividing cells, but also into DNA damaged cells. Therefore, BrdU-positive cells could be dead cells as well. Caspase- 3 is one of the key executioners of apoptosis, being responsible either partially or totally for the proteolytic cleavage of many key proteins. Caspase- 3 is present in the form of proenzyme in the normal cells and activated by apoptotic stimulations $[24,25]$. We found that although caspase-3positive cells were induced at the early stage of renal ischemic injury, a number of BrdU-positive cells do not express the activated form of caspase-3. In addition, caspase-3-positive cells are barely detectable in the renal tissue 4 weeks after injury, while BrdU-positive cells remain at that time point. These findings further suggest that these BrdU-positive cells may be putative proliferative stem or progenitor cells, or dedifferentiation cells. Studies in rodents show that regeneration of tubules starts the second day, reaching 50\% after 10 days [26]. Complete restoration of the tubular morphology may take up to 4 weeks [27, 28], which is similar to the profile of BrdU-positive cells in our study.

Based on our data that the majority of BrdU-positive cells are induced in the renal tubule in response to injury, we assume that dedifferentiation of surviving tubular epithelial cells is the predominant mechanism of cell damage repair after injury. A recent study shows that differentiated epithelial cells that survived injury undergo proliferative expansion, which confirms our findings [11]. Moreover, Vogestseder et al show that the low cycling tubular cell population, involved in tubular proliferation, is differentiated [29]. Although it is possible that other cells in different regions such as dividing interstitial cells may have a role in the repair process, such roles would be at most minor since only a few of BrdU-positive cells are observed in these regions. Consistent with this, a recent study shows that two days after ischemia-reperfusion injury, $50.5 \%$ of outer medullary epithelial cells coexpress Ki67, a proliferative marker. After repair is complete, $66.9 \%$ of epithelial cells have incorporated BrdU, compared to only $3.5 \%$ of cells in the uninjured kidney. These observations indicate that repair of injured nephrons is mainly achieved by intrinsic, surviving tubular epithelial cells.

Interestingly, we found that the BrdU-positive cells in the contralateral side was significantly increased, compare to the normal control. The increased BrdUpositive cells may be due to by cytokines, which is released by injured kidney. Intrinsically stem-like cells in the kidney is on inactive status in the normal condition, but they are activated by the cytokine the ischemiareperfusion injured kidney.

Further understanding of the cellular and molecular mechanisms underlying the regulation of these cell biological behaviors will be essential to developing novel therapeutic strategies for the treatment of ARF.

\section{Acknowledgements}

This work was partially supported by Sir Run Run Shaw Hospital, Zhejiang University School of Medicine to Y.Y., and by University of North Texas Health Sceince Center to K.J.

\section{References}

[1] Pickering MC, Cook HT (2008). Translational minireview series on complement factor $\mathrm{H}$ : renal diseases associated with complement factor $\mathrm{H}$ : novel insights from humans and animals. Clin Exp Immunol, 151: 210230

[2] Bonventre JV, Weinberg JM (2003). Recent advances in the pathophysiology of ischemic acute renal failure. J Am Soc Nephrol, 14: 2199-2210 
[3] Kitamura S, Yamasaki Y, Kinomura M, Sugaya T, Sugiyama H, Maeshima Y, et al. (2005). Establishment and characterization of renal progenitor like cells from S3 segment of nephron in rat adult kidney. FASEB J, 19: 1789-1797

[4] Fujigaki Y, Goto T, Sakakima M, Fukasawa H, Miyaji T, Yamamoto T, et al. (2006). Kinetics and characterization of initially regenerating proximal tubules in S3 segment in response to various degrees of acute tubular injury. Nephrol Dial Transplant, 21: 41-50

[5] Gupta S, Verfaillie C, Chmielewski D, Kren S, Eidman $\mathrm{K}$, Connaire J, et al. (2006). Isolation and characterization of kidney-derived stem cells. J Am Soc Nephrol, 17: 3028-3040

[6] Maeshima A, Sakurai H, Nigam SK (2006). Adult kidney tubular cell population showing phenotypic plasticity, tubulogenic capacity, and integration capability into developing kidney. J Am Soc Nephrol, 17: 188-198

[7] Sagrinati C, Netti GS, Mazzinghi B, Lazzeri E, Liotta F, Frosali F, et al. (2006). Isolation and characterization of multipotent progenitor cells from the Bowman's capsule of adult human kidneys. J Am Soc Nephrol, 17: 24432456

[8] Dekel B, Zangi L, Shezen E, Reich-Zeliger S, EventovFriedman S, Katchman H, et al. (2006). Isolation and characterization of nontubular sca-1+lin- multipotent stem/progenitor cells from adult mouse kidney. J Am Soc Nephrol, 17: 3300-3314

[9] Oliver JA, Maarouf O, Cheema FH, Martens TP, AlAwqati Q (2004). The renal papilla is a niche for adult kidney stem cells. J Clin Invest, 114: 795-804

[10] Bussolati B, Bruno S, Grange C, Buttiglieri S, Deregibus $\mathrm{MC}$, Cantino D, et al. (2005). Isolation of renal progenitor cells from adult human kidney. Am J Pathol, 166: 545-555

[11] Humphreys BD, Valerius MT, Kobayashi A, Mugford JW, Soeung S, Duffield JS, et al. (2008). Intrinsic epithelial cells repair the kidney after injury. Cell Stem Cell, 2: 284-291

[12] Morigi M, Imberti B, Zoja C, Corna D, Tomasoni S, Abbate M, et al. (2004). Mesenchymal stem cells are renotropic, helping to repair the kidney and improve function in acute renal failure. J Am Soc Nephrol, 15: 1794-1804

[13] Lin F, Cordes K, Li L, Hood L, Couser WG, Shankland SJ, et al. (2003). Hematopoietic stem cells contribute to the regeneration of renal tubules after renal ischemiareperfusion injury in mice. J Am Soc Nephrol, 14: 11881199

[14] Kale S, Karihaloo A, Clark PR, Kashgarian M, Krause DS, Cantley LG (2003). Bone marrow stem cells contribute to repair of the ischemically injured renal tubule. J Clin Invest, 112: 42-49

[15] Duffield JS, Park KM, Hsiao LL, Kelley VR, Scadden DT, Ichimura T, et al. (2005). Restoration of tubular epithelial cells during repair of the postischemic kidney occurs independently of bone marrow-derived stem cells. J Clin Invest, 115: 1743-1755

[16] Szczypka MS, Westover AJ, Clouthier SG, Ferrara JL,
Humes HD (2005). Rare incorporation of bone marrowderived cells into kidney after folic acid-induced injury. Stem Cells, 23: 44-54

[17] Jin K, Wang X, Xie L, Mao XO, Zhu W, Wang Y, et al. (2006). Evidence for stroke-induced neurogenesis in the human brain. PNAS, 103: 13198-13202

[18] Dressler GR, Douglass EC (1992). Pax-2 is a DNAbinding protein expressed in embryonic kidney and Wilms tumor. Proc Natl Acad Sci U S A, 89: 1179-1183

[19] Imgrund M, Grone E, Grone HJ, Kretzler M, Holzman L, Schlondorff D, et al. (1999). Re-expression of the developmental gene Pax-2 during experimental acute tubular necrosis in mice 1. Kidney Int, 56: 1423-1431

[20] Cantley LG (2005). Adult stem cells in the repair of the injured renal tubule. Nat Clin Pract Nephrol, 1: 22-32

[21] Lobo MV, Arenas MI, Alonso FJ, Gomez G, Bazan E, Paino CL, et al. (2004). Nestin, a neuroectodermal stem cell marker molecule, is expressed in Leydig cells of the human testis and in some specific cell types from human testicular tumours. Cell Tissue Res, 316: 369-376

[22] Sakairi T, Hiromura K, Yamashita S, Takeuchi S, Tomioka M, Ideura H, et al. (2007). Nestin expression in the kidney with an obstructed ureter. Kidney Int, 72: 307318

[23] Perry J, Ho M, Viero S, Zheng K, Jacobs R, Thorner PS (2007). The intermediate filament nestin is highly expressed in normal human podocytes and podocytes in glomerular disease. Pediatr Dev Pathol, 10: 369-382

[24] Cohen GM (1997). Caspases: the executioners of apoptosis. Biochem J, 326 ( Pt 1): 1-16

[25] Earnshaw WC, Martins LM, Kaufmann SH (1999). Mammalian caspases: structure, activation, substrates, and functions during apoptosis. Annu Rev Biochem, 68: 383-424

[26] Ysebaert DK, De Greef KE, Vercauteren SR, Ghielli M, Verpooten GA, Eyskens EJ, et al. (2000). Identification and kinetics of leukocytes after severe ischaemia/reperfusion renal injury. Nephrol Dial Transplant, 15: 1562-1574

[27] Humes HD, Lake EW, Liu S (1995). Renal tubule cell repair following acute renal injury. Miner Electrolyte Metab, 21: 353-365

[28] Witzgall R, Brown D, Schwarz C, Bonventre JV (1994). Localization of proliferating cell nuclear antigen, vimentin, c-Fos, and clusterin in the postischemic kidney. Evidence for a heterogenous genetic response among nephron segments, and a large pool of mitotically active and dedifferentiated cells. J Clin Invest, 93: 2175-2188

[29] Vogetseder A, Picard N, Gaspert A, Walch M, Kaissling B, Le Hir M (2008). Proliferation capacity of the renal proximal tubule involves the bulk of differentiated epithelial cells. Am J Physiol Cell Physiol, 294: C22-28 